\title{
Cardiac autonomic regulation during exposure to auditory stimulation with classical baroque or heavy metal music of different intensities
}

\author{
Farklı yoğunluklarda klasik barok ve heavy metal müzikle \\ işitsel uyarı sırasında kalbin otonom regülasyonu
}

\author{
Joice A T Amaral, M.D., Marcela L Nogueira, M.D.," Adriano L Roque, M.D.,"\# \\ Heraldo L Guida, M.D.,," Luiz Carlos De Abreu, M.D.,, ${ }^{*}$ Rodrigo Daminello Raimundo, M.D., ${ }^{\dagger}$ \\ Luiz Carlos M Vanderlei, M.D., $\neq$ Vivian L Ribeiro, M.D., $\$$ Celso Ferreira, M.D., $\$$ Vitor E Valenti, M.D.
}

\begin{abstract}
Department of Physiotherapy and Occupational Therapy, Faculty of Philosophy and Sciences, UNESP (Marília), SP; "Department of Speech Language and Hearing Therapy, Faculty of Philosophy and Sciences, UNESP (Presidente Prudente), SP;

*Department of Morphology and Physiology, School of Medicine of ABC, Santo André, SP;

tDepartment of Physiotherapy, Faculty FMU, São Paulo, SP;

‡Department of Physiotherapy, Faculty of Sciences and Technology, Unesp, Presidente Prudente, SP;

§Department of Medicine, Cardiology Division, Federal University of São Paulo, Unifesp, São Paulo, SP, all in Brazil
\end{abstract}

\section{ABSTRACT}

Objectives: The effects of chronic music auditory stimulation on the cardiovascular system have been investigated in the literature. However, data regarding the acute effects of different styles of music on cardiac autonomic regulation are lacking. The literature has indicated that auditory stimulation with white noise above $50 \mathrm{~dB}$ induces cardiac responses. We aimed to evaluate the acute effects of classical baroque and heavy metal music of different intensities on cardiac autonomic regulation.

Study design: The study was performed in 16 healthy men aged 18-25 years. All procedures were performed in the same soundproof room. We analyzed heart rate variability (HRV) in time (standard deviation of normal-to-normal R-R intervals [SDNN], root-mean square of differences [RMSSD] and percentage of adjacent NN intervals with a difference of duration greater than $50 \mathrm{~ms}$ [pNN50]) and frequency (low frequency [LF], high frequency [HF] and LF/HF ratio) domains. HRV was recorded at rest for 10 minutes. Subsequently, the volunteers were exposed to one of the two musical styles (classical baroque or heavy metal music) for five minutes through an earphone, followed by a five-minute period of rest, and then they were exposed to the other style for another five minutes. The subjects were exposed to three equivalent sound levels (60$70 \mathrm{~dB}, 70-80 \mathrm{~dB}$ and $80-90 \mathrm{~dB})$. The sequence of songs was randomized for each individual.

Results: Auditory stimulation with heavy metal music did not influence HRV indices in the time and frequency domains in the three equivalent sound level ranges. The same was observed with classical baroque musical auditory stimulation with the three equivalent sound level ranges.

Conclusion: Musical auditory stimulation of different intensities did not influence cardiac autonomic regulation in men.

\section{ÖZET}

Amaç: Literatürde kardiyovasküler sistem üzerine uzun süreli müzik dinletisinin işitsel uyarıları araştırılmıştır. Ancak farklı müzik türlerinin kalbin otonom regülasyonu üzerine akut etkilerinden söz edilmemiştir. Literatürde $50 \mathrm{~dB}$ üstü beyaz gürültüyle işitsel uyarıya kalbin yanıt verdiği bildirilmiştir. Bu çalışmada, farklı şiddetlerdeki klasik barok ve heavy metal müziğin kalbin otonom regülasyonu üzerindeki akut etkilerini değerlendirmeyi amaçladık.

Çalışma planı: Çalışma 18-25 yaşları arasındaki 16 sağlıklı erkekte uygulandı. İşlemlerin tümü aynı ses geçirmeyen odada yapıldı. Zaman (normal-normal RR intervallerinin standart sapması [SDNN], farklarının karekökü [RMSSD] ve aralarındaki farkın 50 msn'den uzun olduğu komşu NN intervallerinin yüzdesi [pNN50]) ve frekans (düşük frekans [LF], yüksek frekans [HF] ve LF/HF oranı) bazlı kalp hızı değişkenliği (KHD) analizi yapıldı. İstirahatte iken 10 dakika boyunca KHD kaydedildi. Daha sonra gönüllülere bir kulaklık aracılığıyla beş dakika klasik barok veya heavy metal müziği dinletildi. Denekler üç eşdeğer (60-70 dB, 70-80 dB ve 80-90 dB) ses düzeyine maruz bırakıldı. İlk müzik dinletisinden sonra beş dakika istirahatte kaldıktan sonra yeniden klasik barok ve heavy metal müzik dinletildi. Her bir birey için şarkıların sırası rastgele seçilmişti.

Bulgular: Üç eşdeğer ses düzeyinde ve zaman ve ses frekansı alanlarında heavy metal müzikle işitsel uyarı kalp hızı indekslerini etkilemedi. Üç eşdeğer ses düzeyi aralıklarında yapılan klasik barok müzikle işitsel uyarıda da aynı etki gözlenmiştir.

Sonuç: Farklı yoğunluklarda müzikle işitsel uyarı erkeklerde kalbin otonom regülasyonunu etkilememiştir. 
he response
of an organism to musical auditory stimulation was previously investigated. ${ }^{[1]}$ A previous study demonstrated that au-

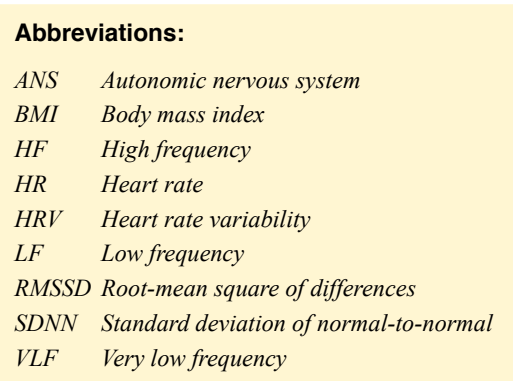

ditory stimulation with a relaxant musical style two hours per day, two days per week over eight weeks improved cardiac autonomic regulation in subjects treated with a cardiotoxic drug; ${ }^{[2]}$ however, its acute effects are still controversial. ${ }^{[1]}$ Conversely, heavy metal musical style was indicated to present negative effects that are associated with stress, including sleep disorders, fatigue, exhaustion, and immunologic activity impairment. ${ }^{[3]}$

The autonomic nervous system (ANS) was reported to be influenced by music. ${ }^{[4]}$ A non-invasive method for investigation of the ANS that describes the oscillations of the intervals between consecutive heartbeats is heart rate variability (HRV). This method describes the fluctuations in the intervals between consecutive heartbeats (RR intervals), which are indicated to influence the sinus node. ${ }^{[5,6]}$ Higher HRV indicates a good physical condition in subjects, with some exceptions, i.e. pathologic arrhythmias. ${ }^{[7]}$

Relaxant music was also shown to reduce arterial blood pressure and sympathetic nervous activity. ${ }^{[8]}$ Authors have suggested that only some styles of musical auditory stimulation influence cardiac autonomic regulation. Furthermore, while the beneficial effects of musical auditory stimulation on HRV have long been known; ${ }^{[2]}$ no previous study has investigated the short-term effects of heavy metal music on HRV.

In this context, white noise is an auditory stimulation that contains equal power within any frequency band with a fixed width, i.e., its sound pressure level is constant. ${ }^{[9]}$ White noise exposure above $50 \mathrm{~dB}$ induces cardiac autonomic responses. ${ }^{[10]}$ However, it is not clear if the intensity of the music affects the cardiovascular system. Considering that a recent study reported that music therapy over two months was able to improve the cardiovascular system in patients treated with cardiotoxic medication, ${ }^{[2]}$ we believe that a characterization of the cardiac autonomic responses to musical auditory stimulation would contribute to the design of future therapies in order to prevent the development of cardiovascular disorders. Thus, this study was undertaken to evaluate the acute effects of auditory stimulation with classical baroque and excitatory heavy metal music of different intensities on cardiac autonomic regulation.

\section{PATIENTS AND METHODS}

\section{Study population}

We analyzed a total of 21 healthy male students, all of whom were nonsmokers aged 18-25 years. All volunteers were informed about the procedures and objectives of the study and, after their agreement, signed a term of informed consent. All study procedures were approved by the Ethics Committee of the Research of the Faculty of Sciences of Universidade Estadual Paulista, Campus of Marilia (Case No. CEP-2011382) and followed the resolution 196/96 National Health 10/10/1996.

\section{Exclusion criteria}

We considered the following exclusion criteria: cardiopulmonary and auditory disorders, psychological, neurological and other impairments that are known to prevent subjects from performing the protocols, and treatment with any drugs that influence cardiac autonomic regulation. We also excluded subjects with previous experience with musical instruments and classical ballet music, as well as volunteers who reported liking heavy metal and baroque musical styles, since its affinity is suggested to affect cardiovascular responses. ${ }^{[11]}$

\section{Initialevaluation}

Before the experimental procedure, volunteers were identified by collecting the following information: age, gender, weight, height, and body mass index (BMI). Anthropometric measurements were obtained according to Lohman. ${ }^{[12]}$ Weight was determined using a digital scale (W 200/5, Welmy, Brazil) with a precision of $0.1 \mathrm{~kg}$. Height was determined using a stadiometer (ES 2020, Sanny, Brazil) with a precision of $0.1 \mathrm{~cm}$ and $2.20 \mathrm{~m}$ of extension. BMI was calculated using the following formula: weight/height, ${ }^{[2]}$ with weight in kilograms and height in meters.

\section{Measurement of auditory stimulation}

The measurements of the equivalent sound levels 
were conducted in a soundproof room using a SV 102 audio dosimeter (Svantek, Poland). It was programmed with the measurement in the "A" weighting circuit, slow response.

The measurement was made during a session lasting a total of four minutes and 50 seconds for the classical baroque music and five minutes and 15 seconds for the excitatory heavy metal music. We used the insert type microphone (MIRE - Microphone in real ear), which was placed inside the auditory canal of the subject, just below the microphone, connected to a personal stereo.

Before each measurement, the microphones were calibrated with the calibrator acoustic CR: 514 model (Cirrus Research plc).

In the analysis, we used Leq (A), which is defined as the equivalent sound pressure level and corresponds to the constant sound level in the same time interval. It contains the same total energy of the sound; we also analyzed the frequency spectrum of the sound stimulation (octave band).

\section{Linear indices of heart rate variability}

The HRV behavior pattern was recorded beat-by-beat throughout the monitoring process at a sampling rate of $1000 \mathrm{~Hz}$. An interval of five minutes was selected during the period of higher signal stability with more than 256 RR intervals, following digital filtering complemented with manual filtering for the elimination of premature ectopic beats and artifacts. Only series with more than $95 \%$ sinus rhythm were included in the study. ${ }^{[13,14]}$

To analyze HRV in the frequency domain, low frequency (LF: 0.04 to $0.15 \mathrm{~Hz}$ ) and high frequency (HF: 0.15 to $0.40 \mathrm{~Hz}$ ) spectral components were used in $\mathrm{ms}^{2}$ and normalized units. Normalizing data of the spectral analysis can be used to minimize the effects of changes in the very low frequency (VLF) band. This is determined by dividing the power of a given component (LF or HF) by the total power spectrum, minus the VLF component and multiplied by 100 . The spectral analysis was calculated using the Fast Fourier Transform algorithm. ${ }^{[15,16]}$

The analysis in the time domain was performed by means of SDNN (standard deviation of normal-tonormal R-R intervals), the percentage of adjacent RR intervals with a difference of duration greater than 50 ms (pNN50) and RMSSD (root-mean square of differences between adjacent normal RR intervals in a time interval). The HRV analysis is a well- recognized method for investigating cardiac autonomic regulation, and HRV is able to detect a poor prognostic in patients with cardiac disorders. ${ }^{[7]}$

For analysis of linear indexes in the time and frequency domains, the Kubios ${ }^{\circledR}$ software was used.

\section{Protocol}

Data collection was carried out in the same soundproof room for all volunteers with the temperature between $21^{\circ} \mathrm{C}$ and $25^{\circ} \mathrm{C}$ and a relative humidity of $50-60 \%$, and volunteers were instructed not to drink alcohol or caffeine for 24 hours before the evaluation. Data were collected on an individual basis, between 6-9 p.m., to standardize the protocol. All procedures necessary for the data collection were explained on an individual basis, and the subjects were instructed to remain at rest and to avoid talking during the collection.

After the initial evaluation, the heart monitor belt was then placed over the thorax, aligned with the distal third of the sternum, and the Polar RS800CX heart rate receiver (Polar Electro, Finland) was placed on the wrist. The subjects were seated and remained at rest with spontaneous breathing for 10 minutes with the earphone turned off.

The HRV indices were compared at the following moments: 1) rest control; 2) music at $60-70 \mathrm{~dB} ; 3$ ) music at 70-80 dB; and 4) music at $80-90 \mathrm{~dB}$. The musical auditory stimulation was an excitatory heavy metal (Gamma Ray: Heavy Metal Universe) and a classical baroque (Pachelbel: Canon in D Major) .The sequence of songs was randomized for each individual.

\section{Statistical analysis}

Standard statistical methods were used for the calculation of means and standard deviations. Normal Gaussian distribution of the data was verified by the Shapiro-Wilk goodness-of-fit test ( $\mathrm{z}$ value $>1.0$ ). For parametric distributions, we applied ANOVA for repeated measures test followed by the Bonferroni posttest. For non-parametric distributions, we used Friedman test followed by the Dunn's posttest. We compared the HRV indices between the three moments. Differences were considered significant when 
Table 1. Baseline diastolic and systolic arterial pressure (DAP, SAP), heart rate (HR), mean RR interval (mean RR), weight, height, and body mass index (BMI) of the volunteers

\begin{tabular}{lc}
\hline Variable & $\begin{array}{c}\text { Value } \\
\text { Mean } \pm S D\end{array}$ \\
\hline Age (years) & $21.8 \pm 2$ \\
Height $(\mathrm{m})$ & $1.68 \pm 8$ \\
Weight $(\mathrm{kg})$ & $65.2 \pm 9$ \\
BMI $\left(\mathrm{kg} / \mathrm{m}^{2}\right)$ & $22.1 \pm 2$ \\
HR $(\mathrm{bpm})$ & $78.4 \pm 8$ \\
Mean RR (ms) & $896.3 \pm 101$ \\
SAP $(\mathrm{mmHg})$ & $123 \pm 5$ \\
DAP $(\mathrm{mmHg})$ & $75 \pm 8$ \\
\hline
\end{tabular}

$\mathrm{m}$ : Meters; kg: Kilograms; bpm: Beats per minute; ms: Milliseconds; $\mathrm{mmHg}$ : Millimeters of mercury.

the probability of a Type I error was less than $5 \%$ $(p<0.05)$. We used the Software GraphPadStatMate version 2.00 for Windows, GraphPad Software, San Diego, California, USA.

\section{RESULTS}

Table 1 shows the values for baseline diastolic (DAP) and systolic arterial pressure (SAP), heart rate (HR), mean RR intervals, weight, height, and BMI of the volunteers.

Regarding the time domain indices of HRV, we observed no significant changes in RMSSD, pNN50 and SDNN indices during exposure to auditory stimulation with excitatory heavy metal (Table 2 ) and classical baroque music styles (Table 3 ) at the three equivalent sound levels.
In relation to the frequency domain indices, we noted that there were no changes in LF and HF indices in absolute and normalized units or in the $\mathrm{LF} / \mathrm{HF}$ ratio during exposure to auditory stimulation with excitatory heavy metal (Table 4 ) and classical baroque music styles (Table 5) at the three equivalent sound levels.

\section{DISCUSSION}

Considering the study of Lee and colleagues ${ }^{[10]}$ that observed cardiac autonomic responses induced by auditory stimulation with white noise above $50 \mathrm{~dB}$ and a positive association between HRV indices and equivalent sound level, we aimed to investigate the cardiac autonomic modulation during exposure to auditory stimulation with excitatory and classical baroque music styles of different intensities. However, we determined that the three equivalent sound levels range $(60-70 \mathrm{~dB}, 70-80 \mathrm{~dB}$ and $80-90 \mathrm{~dB})$ did not significantly influence cardiac autonomic regulation according to the analysis of time and frequency domain indices of HRV.

The parasympathetic modulation of the heart evaluated through time (pNN50 and RMSSD) and frequency (HF in absolute and normalized units) domains indices was not influenced by the classical baroque music style of different intensities used in our study. A previous study ${ }^{[17]}$ performed in rats, which used Mozart's music, reported decreased blood pressure through changes in brain dopaminergic transmission, but HR was not evaluated. An important factor that influenced the author's findings is the procedure used to measure blood pressure, the tail-cuff method. This arterial pressure measurement protocol is indicated to increase the sympathetic activity in animals. ${ }^{[18,19]}$ Therefore, it may bias the arterial blood pres-

\begin{tabular}{|c|c|c|c|c|c|}
\hline \multirow[t]{2}{*}{ Index } & Control & $60-70 \mathrm{~dB}$ & $70-80 \mathrm{~dB}$ & $80-90 \mathrm{~dB}$ & $p$ \\
\hline & Mean \pm SD & Mean \pm SD & Mean \pm SD & Mean \pm SD & \\
\hline RMSSD (ms) & $32.52 \pm 15$ & $32.27 \pm 11$ & $29.11 \pm 10$ & $30.92 \pm 12$ & 0.5 \\
\hline pNN50 & $14.07 \pm 13$ & $12.07 \pm 9$ & $9.58 \pm 7$ & $12.02 \pm 8$ & 0.4 \\
\hline SDNN (ms) & $57.88 \pm 14$ & $49.34 \pm 13$ & $41.4 \pm 266$ & $44.74 \pm 265$ & 0.47 \\
\hline
\end{tabular}

Mean \pm Standard deviation. SDNN: Standard deviation of normal-to-normal R-R intervals; pNN50: Percentage of adjacent RR intervals with a difference of duration greater than $50 \mathrm{~ms}$; RMSSD: Root-mean square of differences between adjacent normal RR intervals in a time interval. ms: Milliseconds. 


\begin{tabular}{|c|c|c|c|c|c|}
\hline \multirow[t]{2}{*}{ Index } & Control & $60-70 \mathrm{~dB}$ & $70-80 \mathrm{~dB}$ & $80-90 \mathrm{~dB}$ & $p$ \\
\hline & Mean \pm SD & Mean $\pm S D$ & Mean $\pm S D$ & Mean $\pm S D$ & \\
\hline RMSSD (ms) & $30.9 \pm 10$ & $25.55 \pm 9$ & $25.3 \pm 9$ & $28.27 \pm 8$ & 0.7 \\
\hline pNN50 & $11.21 \pm 6$ & $7.45 \pm 5$ & $7.82 \pm 6$ & $9.56 \pm 4$ & 0.6 \\
\hline SDNN (ms) & $47.12 \pm 12$ & $36.27 \pm 8$ & $38.02 \pm 9$ & $42.88 \pm 10$ & 0.6 \\
\hline
\end{tabular}

Mean \pm Standard deviation. SDNN: Standard deviation of normal-to-normal R-R intervals; pNN50: Percentage of adjacent RR intervals with a difference of duration greater than 50ms; RMSSD: Root-mean square of differences between adjacent normal RR intervals in a time interval. ms: Milliseconds.

\begin{tabular}{|c|c|c|c|c|c|}
\hline \multirow[t]{2}{*}{ Index } & Control & $60-70 \mathrm{~dB}$ & $70-80 \mathrm{~dB}$ & $80-90 \mathrm{~dB}$ & $p$ \\
\hline & Mean \pm SD & Mean $\pm S D$ & Mean $\pm S D$ & Mean \pm SD & \\
\hline $\mathrm{HF}\left(\mathrm{ms}^{2}\right)$ & $415 \pm 298$ & $339.42 \pm 207$ & $283 \pm 170$ & $325.57 \pm 191$ & 0.5 \\
\hline $\mathrm{LF}\left(\mathrm{ms}^{2}\right)$ & $1433 \pm 642$ & $1027 \pm 696$ & $809 \pm 588$ & $822 \pm 430$ & 0.6 \\
\hline $\mathrm{HF}(\mathrm{nu})$ & $21.48 \pm 12$ & $25.84 \pm 18$ & $28.75 \pm 15$ & $26.62 \pm 10$ & 0.45 \\
\hline LF (nu) & $78.48 \pm 12$ & $74.12 \pm 18$ & $71.2 \pm 15$ & $73.3 \pm 10$ & 0.67 \\
\hline LF/HF & $3.1 \pm 1$ & $3.2 \pm 0.3$ & $2.8 \pm 0.9$ & $3.9 \pm 2$ & 0.5 \\
\hline
\end{tabular}

Mean \pm Standard deviation. LF: Low frequency; HF: High frequency; LF/HF: Low frequency/High frequency ratio; ms: Milliseconds.

\begin{tabular}{|c|c|c|c|c|c|}
\hline \multirow[t]{2}{*}{ Index } & Control & $60-70 \mathrm{~dB}$ & $70-80 \mathrm{~dB}$ & $80-90 \mathrm{~dB}$ & $p$ \\
\hline & Mean $\pm S D$ & Mean \pm SD & Mean \pm SD & Mean \pm SD & \\
\hline HF (ms2) & $370.87 \pm 261.27$ & $214 \pm 50$ & $210.75 \pm 110$ & $221.1 \pm 114$ & 0.56 \\
\hline LF (ms2) & $1047.37 \pm 748$ & $553 \pm 246.02$ & $521 \pm 169$ & $683 \pm 358$ & 0.77 \\
\hline $\mathrm{HF}(\mathrm{nu})$ & $25.27 \pm 10.76$ & $26.15 \pm 15$ & $26.2 \pm 10$ & $25.62 \pm 16$ & 0.45 \\
\hline LF (nu) & $75.57 \pm 11.76$ & $73 \pm 15$ & $73.71 \pm 10$ & $74.33 \pm 16$ & 0.54 \\
\hline LF/HF & $3.68 \pm 1.62$ & $3.48 \pm 0.29$ & $2.42 \pm 0.03$ & $4.74 \pm 5.71$ & 0.58 \\
\hline
\end{tabular}

Mean \pm Standard deviation. LF: Low frequency; HF: High frequency; LF/HF: Low frequency/High frequency ratio. ms: Milliseconds.

sure data. It is possible that the music reduced arterial blood pressure due to a relaxant mechanism in response to the stress caused by the tail-cuff method, not influencing the basal HR.

Based on our data, classical baroque musical auditory stimulation of different intensities did not acutely change the SDNN. The SDNN is the time domain in- dex that corresponds to the global HRV. ${ }^{[7]}$ Conversely, a previous study ${ }^{[2]}$ investigated the chronic effects of music therapy on patients with cancer who were treated with a cardiotoxic medication. The authors reported that music stimulation over 10 weeks improved the SDNN index. In their study, the patients were exposed to popular Taiwanese songs with pleasant, moderate 
rhythms and tempos. The activity proposed by the authors also involved learning how to play musical instruments and featured different instruments in each session. We believe that the different styles of music and the addition of activities in the therapy are important factors that influenced the cardiac autonomic modulation of the patients evaluated in the study of Chuang and coworkers, ${ }^{[2]}$ the results of which were not similar to our data.

We also investigated the effects of auditory stimulation with heavy metal music of different intensities on cardiac autonomic regulation. Although we expected to observe a significant influence of this music style on the sympathetic modulation of the heart, heavy metal music demonstrated no significant effect on HRV in the three equivalent sound level ranges. The literature has reported that excitatory music such as techno influences the neuroendocrine system in humans, ${ }^{[20]}$ and it was observed that listening to techno music led to a significant increase in the levels of HR, noradrenaline, cortisol, and adrenocorticotropic hormone. Previous studies have shown the chronic beneficial effects of relaxing classical music while genres like hip hop, techno and heavy metal are suggested to be commonly associated with physiological arousal. ${ }^{[20,21]}$ Heavy metal music was even indicated not only to be ineffective but able to induce stress and/or lifethreatening arrhythmias, ${ }^{[22]}$ and most studies found an increase in HR during excitatory music stimulation. ${ }^{[23,24]}$ However, a careful literature search of the PubMed database did not reveal any study that has investigated HRV responses to heavy metal musical auditory stimulation.

Based on our data, the different ranges of equivalent sound level of the two selected music styles did not significantly affect the autonomic regulation of the heart. A previous study showed that auditory stimulation with white noise influenced the sympathetic regulation of the heart through analysis of frequency domain indices. ${ }^{[10]}$ Although the authors did not observe changes in HR or arterial blood pressure, they found an increase in the LF/HF ratio with a five-minute binaural presentation of white noise of low-to-moderate intensity. Furthermore, a significant correlation between the LF/HF ratio and the equivalent sound level of the white noise was also noted. Nonetheless, there are differences between white noise and the excitatory heavy metal/classical baroque musical stimulation used in our investigation. The white noise presents a very small range in its equivalent sound level, ${ }^{[25]}$ while music has a larger range of intensity. Musical auditory stimulation affects memory and emotions, ${ }^{[23,24]}$ whereas white noise has no significant influence on these cognitive functions. Taken together, it is suggested that the intensity of the auditory stimulation depends on its category.

The relationship between auditory stimulation intensity and cardiac responses is based on the acoustic startle reflex, which is the effect of loud sounds on the cardiovascular system. It is considered as a sudden reaction of arterial blood pressure and HR to an abrupt loud auditory stimulation. ${ }^{[26]}$ The usual intensity to induce the acoustic startle reflex is around $110 \mathrm{~dB},{ }^{[26]}$ which is much lower than the classical baroque and excitatory heavy metal music investigated in our study (up to $90 \mathrm{~dB}$ ). However, this reflex cannot be evaluated through HRV. HRV analysis in the frequency domain through Fast Fourier Transform needs a sample of $256 \mathrm{RR}$ intervals, ${ }^{[27]}$ which requires a minimal period of 3-5 minutes, and the startle reflex spends only a few seconds.

In order to avoid gender differences regarding the cardiac autonomic responses to musical auditory stimulation, our study included only men. Previous researches regarding gender differences with respect to emotional expression and experience have presented conflicting results. ${ }^{[28,29]}$ In this context, music is a potent emotion-eliciting stimulation. ${ }^{[23,24]}$ One study suggested that women are more stress-reactive compared with men in response to music. ${ }^{[21]}$ Different groups indicated that sex-based differences in psychophysiological responses to music are strongly influenced by hormonal status. ${ }^{[30]}$ On the other hand, studies describing differences between men and women in relation to the cardiac autonomic responses to music or other auditory stimulation styles are lacking in the literature.

Although we did not find significant effects of excitatory and classical baroque musical auditory stimulation of different intensities on cardiac autonomic regulation, previous studies have proposed some physiological mechanisms involved in the effects of music on the ANS. It was suggested that musical emotions induce skin conductance responses based on its arousal. ${ }^{[31]}$ Another study indicated that music recruits neural mechanisms of emotion and reward 
similar to those known to respond specifically to biologically relevant stimuli, such as food and sex, and those that are artificially activated by drugs of abuse. ${ }^{[24]}$ Supporting this data, Salimpoor et al. ${ }^{[32]}$ observed a temporal dissociation between distinct regions of the striatum while listening to enjoyable music. The combined neurochemical, psychophysiological and hemodynamic method used by the authors showed that peaks of ANS activity, which reflect the experience of the most intense emotional moments, were associated with dopamine release in the nucleus accumbens. This region has been implicated in the euphoric component of psychostimulants, such as cocaine. ${ }^{[33]}$ On the other hand, we failed to find effects of excitatory and classical baroque music on cardiac autonomic regulation. We believe that the autonomic changes that occur during musical auditory stimulation spend less than the period able to provide 256 beats, the minimal number recommended to analyze HRV. This fast and acute response was proposed by Khalfa and coworkers ${ }^{[34,35]}$ by analyzing skin conductance response, which corresponds to sympathetic activity.

Some important points regarding the method in our study should be mentioned. We studied two music titles, each one corresponding to different musical styles. The styles investigated do not include uniform songs or titles with respect to various variables such as instruments, tempo, and emotion induction. Therefore, we cannot conclude that all classical baroque and heavy metal musical styles would have no effect on HRV.

In conclusion, auditory stimulation with classical baroque and excitatory heavy metal music styles of different intensities did not influence cardiac autonomic modulation in men. We suggest that the equivalent sound level range in those specific music styles has no significant effect on the sympathetic and parasympathetic modulation of the heart.

\section{Conflict-of-interest issues regarding the authorship or article: None declared}

\section{REFERENCES}

1. Valenti VE, Guida HL, Frizzo AC, Cardoso AC, Vanderlei LC, Abreu LC. Auditory stimulation and cardiac autonomic regulation. Clinics (Sao Paulo) 2012;67:955-8. CrossRef

2. Chuang CY, Han WR, Li PC, Song MY, Young ST. Effect of long-term music therapy intervention on autonomic function in anthracycline-treated breast cancer patients. Integr Cancer
Ther 2011;10:312-6. CrossRef

3. Yamasaki A, Booker A, Kapur V, Tilt A, Niess H, Lillemoe $\mathrm{KD}$, et al. The impact of music on metabolism. Nutrition 2012;28:1075-80. CrossRef

4. Bernardi L, Porta C, Casucci G, Balsamo R, Bernardi NF, Fogari R, et al. Dynamic interactions between musical, cardiovascular, and cerebral rhythms in humans. Circulation 2009;119:3171-80. CrossRef

5. Valenti VE, Vanderlei LC, Ferreira C, Fonseca FL, Oliveira FR, Sousa FH, et al. Sidestream cigarette smoke and cardiac autonomic regulation. Int Arch Med 2013;6:11. CrossRef

6. Abreu LC: Heart rate variability as a functional marker of development. J Hum Growth Developm 2012:22:279-81.

7. Vanderlei LC, Pastre CM, Hoshi RA, Carvalho TD, Godoy MF. Basic notions of heart rate variability and its clinical applicability. Rev Bras Cir Cardiovasc 2009;24:205-17. CrossRef

8. Nakamura T, Tanida M, Niijima A, Hibino H, Shen J, Nagai K. Auditory stimulation affects renal sympathetic nerve activity and blood pressure in rats. Neurosci Lett 2007;416:107-12.

9. Roque AL, Valenti VE, Guida HL, Campos MF, Knap A, Vanderlei LC, et al. The effects of auditory stimulation with music on heart rate variability in healthy women. Clinics (Sao Paulo) 2013;68:960-7. CrossRef

10. Lee GS, Chen ML, Wang GY. Evoked response of heart rate variability using short-duration white noise. Auton Neurosci 2010;155:94-7. CrossRef

11. Harrer G, Harrer H. Music, emotion and the autonomic nervous system. [Article in German] Wien Med Wochenschr 1968;118:966-71. [Abstract]

12. Lohman T, Martorell R, Roche AF. Anthropometric standardization reference manual. Champaign, IL: Human Kinetics Books; 1988.

13. Moreno IL, Pastre CM, Ferreira C, de Abreu LC, Valenti VE, Vanderlei LC. Effects of an isotonic beverage on autonomic regulation during and after exercise. J Int Soc Sports Nutr 2013;10:2. CrossRef

14. Raimundo RD, de Abreu LC, Adami F, Vanderlei FM, de Carvalho TD, Moreno IL, et al. Heart rate variability in stroke patients submitted to an acute bout of aerobic exercise. Transl Stroke Res 2013;4:488-99. CrossRef

15. Pivatelli FC, Dos Santos MA, Fernandes GB, Gatti M, de Abreu LC, Valenti VE, et al. Sensitivity, specificity and predictive values of linear and nonlinear indices of heart rate variability in stable angina patients. Int Arch Med 2012;5:31.

16. Koca B, Bakari S, Oztunç F. Correlation among the heart rate variability indices in healthy children and those with atrial septal defect. Turk Kardiyol Dern Ars 2013;41:193-8. CrossRef

17. Sutoo D, Akiyama K. Music improves dopaminergic neurotransmission: demonstration based on the effect of music on blood pressure regulation. Brain Res 2004;1016:255-62. CrossRef

18. Abu-Taha I, Lemmer B. Superiority of radiotelemetry over the tail-cuff method in evaluating control and drug-induced values in cardiovascular functions in rats. Naunyn-Schmiede- 
berg's Arch Pharmacol 2007;375(Suppl 1):R313.

19. Whitesall SE, Hoff JB, Vollmer AP, D’Alecy LG. Comparison of simultaneous measurement of mouse systolic arterial blood pressure by radiotelemetry and tail-cuff methods. Am J Physiol Heart Circ Physiol 2004;286:H2408-15. CrossRef

20. Gerra G, Zaimovic A, Franchini D, Palladino M, Giucastro G, Reali N, et al. Neuroendocrine responses of healthy volunteers to 'techno-music': relationships with personality traits and emotional state. Int J Psychophysiol 1998;28:99-111.

21. Nater UM, Abbruzzese E, Krebs M, Ehlert U. Sex differences in emotional and psychophysiological responses to musical stimuli. Int J Psychophysiol 2006;62:300-8. CrossRef

22. Trappe HJ. The effects of music on the cardiovascular system and cardiovascular health. Heart 2010;96:1868-71. CrossRef

23. Burns JL, Labbé E, Arke B, Capeless K, Cooksey B, Steadman A, et al. The effects of different types of music on perceived and physiological measures of stress. J Music Ther 2002;39:101-16. CrossRef

24. Blood AJ, Zatorre RJ. Intensely pleasurable responses to music correlate with activity in brain regions implicated in reward and emotion. Proc Natl Acad Sci U S A 2001;98:1181823. CrossRef

25. Daee S, Wilding JM. Effects of high intensity white noise on short-term memory for position in a list and sequence. $\mathrm{Br} \mathbf{J}$ Psychol 1977;68:335-49. CrossRef

26. Turpin G, Siddle DA. Cardiac and forearm plethysmographic responses to high intensity auditory stimulation. Biol Psychol 1978;6:257-81. CrossRef

27. Heart rate variability: standards of measurement, physiological interpretation and clinical use. Task Force of the European Society of Cardiology and the North American Society of
Pacing and Electrophysiology. Circulation 1996;93:1043-65.

28. Bradley MM, Codispoti M, Sabatinelli D, Lang PJ. Emotion and motivation II: sex differences in picture processing. Emotion 2001;1:300-19. CrossRef

29. Kring AM, Gordon AH. Sex differences in emotion: expression, experience, and physiology. J Pers Soc Psychol 1998;74:686-703. CrossRef

30. Chikahisa S, Sano A, Kitaoka K, Miyamoto K, Sei H. Anxiolytic effect of music depends on ovarian steroid in female mice. Behav Brain Res 2007;179:50-9. CrossRef

31. Yamasaki A, Booker A, Kapur V, Tilt A, Niess H, Lillemoe $\mathrm{KD}$, et al. The impact of music on metabolism. Nutrition 2012;28:1075-80. CrossRef

32. Salimpoor VN, Benovoy M, Longo G, Cooperstock JR, Zatorre RJ. The rewarding aspects of music listening are related to degree of emotional arousal. PLoS One 2009;4:e7487. CrossRef

33. Volkow ND, Wang GJ, Fischman MW, Foltin RW, Fowler JS, Abumrad NN, et al. Relationship between subjective effects of cocaine and dopamine transporter occupancy. Nature 1997;386:827-30. CrossRef

34. Khalfa N, Bertrand PR, Boudet G, Chamoux A, Billat V. Heart rate regulation processed through wavelet analysis and change detection: some case studies. Acta Biotheor 2012;60:109-29.

35. Labbé E, Schmidt N, Babin J, Pharr M. Coping with stress: the effectiveness of different types of music. Appl Psychophysiol Biofeedback 2007;32:163-8. CrossRef

Key words: Acoustic stimulation; affect; autonomic nervous system; blood pressure/physiology; cardiovascular system; emotions; music.

Anahtar sözcükler: Akustik stimülasyon; etki; otonom sinir sistemi; kan basıncı/fizyoloji; kardiyovasküler sistem; duygular; müzik. 